\title{
Correction to: Air quality and acute myocardial infarction in adults during the 2016 Hangzhou G20 summit
}

\author{
Ming-Wei Wang ${ }^{1} \cdot$ Juan $\mathrm{Chen}^{2} \cdot$ Ran Cai $^{3}$
}

Published online: 15 February 2018

(C) Springer-Verlag GmbH Germany, part of Springer Nature 2018

\section{Correction to: Environ Sci Pollut Res}

$$
\text { https://doi.org/10.1007/s11356-017-1136-2 }
$$

Unfortunately, the original publication of this paper contains a mistake. The correct name of the 1st Author is Ming-Wei Wang.

The original article has been corrected.

The online version of the original article can be found at https://doi.org/ $10.1007 / \mathrm{s} 11356-017-1136-2$

\footnotetext{
Juan Chen

chenjuan564453@163.com

1 Division of Cardiology, The Affiliated Hospital of Hangzhou Normal University, Hangzhou 310015, China

2 Division of Ophthalmology, The Affiliated Hospital of Hangzhou Normal University, Hangzhou 310015, China

3 Zhejiang Provincial Center for Disease Control and Prevention, Hangzhou, China
} 